\title{
Cross-Reactions Among Carbonic Anhydrases I, II, and III Studied by Binding Tests and with Monoclonal Antibodies
}

\author{
Robert P. Erickson, ${ }^{1,2}$ Gary Kay, ${ }^{1}$ David Hewett-Emmett, ${ }^{1}$ Richard E. \\ Tashian, ${ }^{1}$ and J. Latham Claflin ${ }^{3}$
}

Received 9 Oct. 1981-Final 19 Feb. 1982

Cross-reactions among carbonic anhydrases (CAs) I, II, and III were studied using a variety of antisera: (1) a rabbit antiserum to bovine CA III, (2) mouse antisera to human CA I, CA II, and CA III; and (3) five monoclonal antibodies prepared by the hybridoma technique using splenocytes from a mouse immunized with human CAs I and II and bovine CA III. Crossreactions between $C A s$ were readily found by binding assays using these antisera. Human $C A I$, but not human $C A I I$, inhibited the reaction of the rabbit anti-CA III with its homologous antigen. Mouse antisera to CA I or CA II bound the homologous I or II with nearly as great efficiency as the autologous isozyme and sometimes weakly bound CA III. Mouse antisera to CA III frequently bound CA I or II. These cross-reactions were confirmed by the first use of hybridoma-prepared, monoclonal antibodies to CAs. The mouse monoclonal antibodies to CA isozymes varied in the amount of cross-reactivity among I, II, and III: at one extreme, one monoclonal was highly specific for the autologous CA III; at the other extreme, one monoclonal weakly reacted with some examples of CAs I, II, and III.

KEY WORDS: carbonic anhydrase; isozymes; immunological cross-reactions; monoclonal antibodies; protein evolution.

This work was supported by NIH Grant GM-24681 and a grant from the National FoundationMarch of Dimes.

${ }^{1}$ Department of Human Genetics, University of Michigan Medical School, Ann Arbor, Michigan 4.8109 .

${ }^{2}$ To whom correspondence should be addressed.

${ }^{3}$ Department of Microbiology and Immunology, University of Michigan Medical School, Ann Arbor, Michigan 48109. 


\section{INTRODUCTION}

The carbonic anhydrases (CA; EC 4.2.1.1) catalyze the hydration of $\mathrm{CO}_{2}$ and the dehydration of $\mathrm{HCO}_{3}^{-}$and are known to occur in most prokaryotes and eukaryotes that have been examined. Three isozymes of carbonic anhydrase, CA I, CA II, and CA III, which are under the control of separate genetic loci, have now been characterized from vertebrate tissues. CA I (low-activity form) is found mainly in red cells and some other tissues (e.g., rumen epithelium, cecum, colonic mucosa, ciliary body), CA II (high-activity form) is found in red cells and almost all tissues, and CA III (low-activity, sulfonamideresistant form) is found primarily in red skeletal muscle and rat liver (cf. Tashian, 1977; Tashian et al., 1980a,b; Kishida and Ochi, 1980; Carter et al., 1981). Also, a particulate-bound form of CA has been reported from human kidney (McKinley and Whitney, 1976) and a mitochondrial CA has been found in guinea pig skeletal muscle and liver (Dodgson et al., 1980). These may represent additional isozymes of $\mathrm{CA}$.

Comparisons of the primary structures of various mammalian CA I, CA II, and CA III isozymes show a considerable degree of sequence homology (i.e., about $40 \%$ of the residues at the same positions are identical), indicating that these isozymes arose from a common gene by duplications well over 300 million years ago (Tashian et al., 1980a). Antibodies prepared against a single isozyme will cross-react with varying intensities by immunoprecipitation with the same isozyme from widely separated species (cf. Tashian et al., 1968; Suyama et al., 1968a; Nonno et al., 1969; Fine and Laurent, 1970). However, immunological cross-reactions have not been detected between isozymes, not even between the highly homologous (about 60\%) CA I and CA II sequences of a single mammalian species, e.g., human (cf. Micheli and Buzzi, 1964; Tashian et al., 1968; Suyama et al., 1968b; Fine and Laurent, 1970). Since only immunoprecipitation procedures have been used in these studies, it seemed probable that cross-reactions would be observed with the use of more sensitive binding assays. We report here the results of such assays in which cross-reactions were observed between various $\mathrm{CA}$ isozymes found by the use of a variety of antisera, including monoclonal antisera prepared by the hybridoma technique.

\section{MATERIALS AND METHODS}

\section{Purification of Antigens}

The CA I and CA II antigens (Table I) were purified from hemolysates by affinity chromatography on sulfonamide (Prontosil) columns as described by Osborne and Tashian (1975). The CA III antigens were initially prepared 
Table I. Carbonic Anhydrase Isozymes from Various Species Used in Cross-Reactivity Tests (Plus Other Control Proteins)

\begin{tabular}{llll}
\hline CA I & \multicolumn{1}{c}{ CA II } & CA III & \multicolumn{1}{c}{ Control } \\
\hline Human & Ox & Ox & Bovine serum albumin \\
& Domestic cat & Chicken & Hemoglobin \\
& Human & Elephant & Soybean trypsin inhibitor \\
& Mouse & Gorilla & \\
& Rabbit & Human & \\
& Rhesus macaque & Rabbit & \\
& Sheep & & \\
& Rat & & \\
\hline
\end{tabular}

from skeletal muscle homogenates by similar affinity chromatography (Osborne and Tashian, 1975) on columns equilibrated with 0.01 or $0.005 \mathrm{M}$ Tris- $\mathrm{SO}_{4}, p \mathrm{H} 8.7$, and eluted with a $0-0.4 M \mathrm{KI}$ gradient, followed by purification on DEAE-32 cellulose columns equilibrated with $0.01 \mathrm{M}$ Tris$\mathrm{HCl}, p \mathrm{H} 8.7$, and eluted with a $0-0.2 \mathrm{M} \mathrm{NaCl}$ gradient. If necessary, further purification of CA III was carried out by passage through a G-75 Sephadex column equilibrated with $0.05 \mathrm{M}$ Tris- $\mathrm{HCl}, p \mathrm{H}$ 8.0. The solutions used in the purification of the CA III isozymes contained $0.5 \mathrm{~mm}$ dithiothreitol.

\section{Immunizations}

Individual anti-CA sera were obtained by immunizing $\mathrm{BC} 8(\mathrm{C} 57 \mathrm{BL} / 6$. C-Igh ${ }^{a}$ ) mice with $200 \mu \mathrm{g}$ of either human CA I, human CA II, or bovine CA III at weekly intervals by the intraperitoneal route. The antigen was diluted with Dulbecco's $\mathrm{CA}^{2+}, \mathrm{mg}^{2+}$-free phosphate-buffered saline (PBS) so as to be delivered in $0.5 \mathrm{ml}$ in a 50:50 homogenate with Freund's adjuvant, complete for the first injection and incomplete thereafter. A series of four injections was given, followed by a 6 -week rest, and the immunization series was terminated with a $50-\mu \mathrm{g}$ boost given in a similar volume.

BALB/c mice were immunized with a mixture of human CAs I and II and bovine CA III in preparation for producing monoclonal antibodies by the hybridoma technique. The triple immunization allowed us to obtain monoclonal antibodies to more than one isozyme from one fusion. To accomplish this, the mice were given a series of intraperitoneal injections at 2-week intervals of $0.2 \mathrm{ml}$ of a $1: 1$ carbonic anhydrase $(1.8-3.7 \mathrm{mg} / \mathrm{ml}$ in PBS):adjuvant solution (a dosage of $0.07-0.17 \mathrm{mg}$ of each antigen). For the initial two injections, complete Freund's adjuvant was used; subsequent injections were done in incomplete Freund's adjuvant. Sera were obtained 2-5 days postinjection by tail bleeding the mice. After the serum titer has reached $1 / 1000$ by the antigen immunoadsorption test described below, the mice were given a final 
intravenous injection of $0.1 \mathrm{ml}$ of a saline solution containing $35 \mu \mathrm{g}$ of each antigen. Three days later, their spleens were removed and fused.

Antibody to bovine CA III was prepared in a New Zealand white rabbit by subcutaneous injections of a mixture containing $1 \mathrm{mg}$ purified CA III in 0.8 $\mathrm{ml} 0.85 \%$ saline and $0.8 \mathrm{ml}$ Freund's complete adjuvant. The same procedure (with Freund's incomplete adjuvant) was followed after a period of 3 weeks, with additional injections at weekly intervals for the following 2 weeks. The rabbit was bled 1 week after the last injection.

\section{Production of Monoclonal Antibodies}

The fusion technique was a modification of that described by Gefter et al. (1977). The specific details can be found elsewhere (Claflin et al., 1981). Myeloma cells (SP2/O-Ag 14) were grown in suspension in supplemental Dulbecco's modified Eagle (DME) $+15 \%$ fetal calf serum. Cells were fused in DMA + $20 \mathrm{mM}$ Hepes buffer, and the fused cells were cloned in Iscove's modified DME (GIBCO, Grand Island, N.Y.) supplemented with $20 \%$ fetal calf serum, $10 \%$ NCTC $109,1 \%$ Pen-Strep, and $3.024 \mathrm{~g}$ of $\mathrm{NaHCO}_{3}$ per liter of solution. Hybrid cells were selected in a HAT medium consisting of the supplemented Iscove's described above with $100 \mu \mathrm{M}$ hypoxanthine, $10 \mu \mathrm{M}$ aminopterin, and $30 \mu \mathrm{M}$ thymidine (Margulies et al., 1976; Littlefield, 1964).

Following fusion, the cells were seeded into 96-well cluster dishes (Costar, Cambridge, Mass.), and these dishes were examined for clones. When clones covered $10-20 \%$ of the surface area of the wells, supernatants were assayed for the presence of anti-human CA I, anti-human CA II, or antibovine CA III by the absorbed antigen radioimmunoassay.

\section{Radioimmunoassays}

Serum and hybridoma supernatants were measured by an absorbed antigen radioimmunoassay previously described (Klinman, 1972). Serum or supernatant dilutions were added to polyvinyl chloride microtiter plates (Cook Laboratory Products Division, Dynatech Laboratories, Inc., Alexandria, Va.) precoated with $0.2 \mathrm{ml}$ of a $20 \mu \mathrm{g} / \mathrm{ml}$ antigen solution per well, then with $\gamma$-globulin-free fetal calf serum (10\%) as a source of blocking protein. After the plates were washed, bound antibody was assayed by the addition of ${ }^{125}$ I-labeled anti-mouse IgG or anti-mouse Fab; wells were cut out and counted, using wells coated with $1 \%$ BSA in PBS as a control.

Competitive inhibitions between antigens were performed using an antibody-absorbed solid-phase radioimmunoassay. A dilution of antibody predetermined to give maximal binding of ${ }^{125}$ I-antigen was allowed to adsorb on polyvinyl chloride microtiter plates for $6 \mathrm{hr}$ at room temperature. The wells 
were washed $2 \times$ with PBS-azide $(0.01 \% \mathrm{Na}$-azide) and allowed to soak for several hours in $1 \%$ ovalbumin in PBS-azide at room temperature. The ovalbumin was removed by aspiration and $0.2 \mathrm{ml}$ of a radioactive solution consisting of various dilutions of inhibitors in $1 \%$ ovalbumin-PBS containing ${ }^{125} \mathrm{I}$-CA $(30,000$ to $60,000 \mathrm{cpm} / \mathrm{ml})$ was added. The microtiter plate was incubated at $37^{\circ} \mathrm{C}$ overnight in a humidified chamber, washed $3 \times$ with PBS-azide, and dried, and each well was cut out and counted.

\section{Radiolabeling}

Rabbit anti-mouse IgG (Gateway Immunosera, St. Louis, Mo.) or rabbit anti-mouse Fab (Rudikoff et al., 1972) was labeled with ${ }^{125}$ I while bound to mouse IgG columns (Herzenberg and Herzenberg, 1978).

Bovine CA III was iodinated by the iodogen method (Fraker and Speck, 1978). Briefly, $20 \mu \mathrm{g}$ of bovine CA III was incubated with $200 \mu \mathrm{Ci} \mathrm{Na}{ }^{125} \mathrm{I}$ for $1 \mathrm{~min}$ at room temperature in a chloroglycoluril-coated tube in $100 \mu \mathrm{l}$ of 0.7 $\mathrm{MNaCl}, 0.2 \mathrm{M}$ potassium phosphate, $p \mathrm{H}$ 7.0. The ${ }^{125} \mathrm{I}-\mathrm{CA}$ was separated from $\mathrm{Na}{ }^{125} \mathrm{I}$ on Sephadex $\mathrm{G}-25$ by collection $0.5-\mathrm{ml}$ samples in tubes which already contained a drop of $1 \%$ ovalbumin. The two tubes containing the first peak were pooled with rinses of $1 \%$ ovalbumin in PBS and then dialyzed for further removal of free $\mathrm{NA}^{125} \mathrm{I}$. The final specific activity was $0.3 \mu \mathrm{CI} / \mu \mathrm{g}$.

\section{RESULTS}

The binding of ${ }^{125}$ I-bovine CA III by rabbit anti-bovine CA III serum was strongly inhibited by cold bovine CA III and weakly inhibited by cold human CA I (Fig. 1). The inhibition by the cross-reacting CA I was 3 orders of magnitude weaker than the autologous reaction and it did not go to completion. Human CA II did not significantly inhibit the binding of bovine CA III by its autologous antibody.

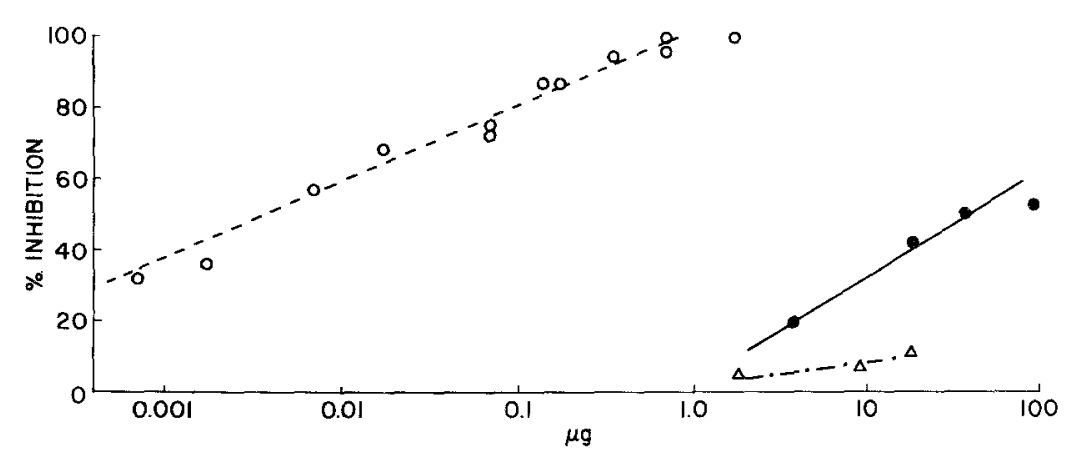

Fig. 1. Inhibition of binding of $30 \mathrm{ng}{ }^{125}$ I-bovine CA III to immunoadsorbed rabbit anti-bovine CA III by $(O)$ bovine CA III, $(\bullet)$ human CA I, and $(\Delta)$ human CA II. 
Cross-reactions of anti-CA antibodies were studied in more detail using direct immunoadsorption of mouse anti-CA antibodies. A number of sera were tested and most showed cross-reactions between isozymes. Several representative patterns are shown in Fig. 2. Antisera to CA I or CA II frequently reacted nearly as well to the other red blood-cell isozyme as to the autologous antigen, e.g., anti-I in Fig. 2A and anti-II in Fig. 2C. The anti-CA I or II usually also reacted quite well with CA III (even from a different species) (Figs. 2A and C). Some antisera showed much stronger binding reactions with autologous antigen than with other $\mathrm{CA}$ isozymes, e.g., another anti-I in Fig. 2D. Antisera to Ca III were usually weaker than antisera to CA I or II but they frequently showed good cross-reactions with CA I or II, e.g., Fig. 2B demonstrates a cross-reaction of anti-III with CA II; similar reactions with CA I were sometimes found (not shown).

We sought to understand further the nature of the cross-reactions between the CA isozymes by using monoclonal antibodies prepared by the hybridoma technique. The fusion of the mice spleen cells with the SP2 myeloma cells resulted in 644 microtiter wells, of which 32 yielded clones, an efficiency rate of $5 \%$. Of these 32 clones, 8 showed anti-carbonic anhydrase

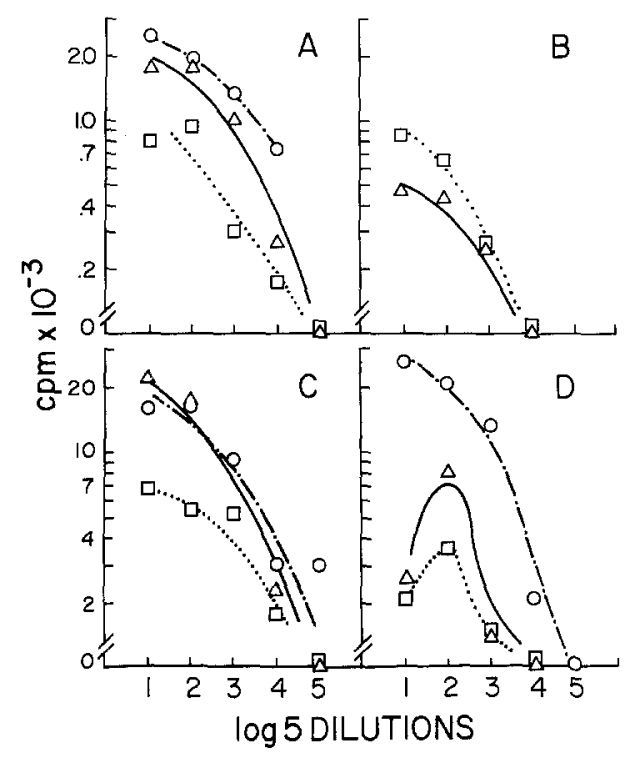

Fig. 2. Cross-reactions in the antigen immunoadsorption test of individual mouse antisera to human CA I (A, D), human CA III (B), and human CA II (C) with human CA I ( $\cdot-\mathrm{O}-\cdot)$, human CA II $(-\Delta-)$, and human $\mathrm{CA}$ III $(\cdots \square \cdots)$. 
activity (25\% of the clones and $1.25 \%$ of the total fusion). The reactivity of the hybridoma supernatants was determined by a counting ratio of the reaction of the antibody with the carbonic anhydrase to the antibody with bovine serum albumin:

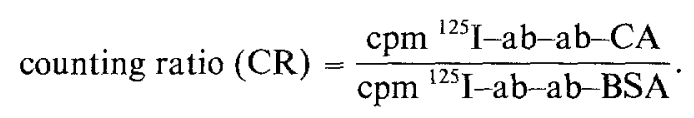

All the monoclonal supernatants were tested for immunoprecipitation with all three antigens by double diffusion and all were negative as is expected for the reaction of a monoclonal antibody with a monomeric antigen. Table II indicates the cross-reactivity patterns of supernatants from five of the eight positive clones (three lost secretory activity too early for testing). The especially significant results in Table II are italicized. Several interesting patterns are readily seen. Clone $2 \mathrm{G}-4$ reacted well with bovine CA III, one of the antigens used to immunize the triply immunized mice, and not at all with any other CA isozymes, including other CA III's. Clone $12 \mathrm{C}-8$ probably originated from the fusion of a spleen cell which had responded to human $\mathrm{CA}$ II since the strongest reactions occurred with CA II from three species. A nearly equivalent reaction occurred to human $\mathrm{CA} I$ and significant reactions occurred with chicken and rabbit CA III. Clone 2B-7 was presumably also directed against human CA II but reacted more strongly with rhesus CA II than with the autologous antigen. This monoclonal antibody also reacted with some CA III's. Similarly, clone 10E-3 reacted most strongly with human and rat CA II and moderately with several CA III's. Clone 2D-2 reacted weakly with almost all CA isozymes - the concentration of antibody in this supernatant may have been lower than that with the other clones.

\section{DISCUSSION}

The population of antibody molecules resulting from immunization with various poly- $\alpha$-amino acids clearly includes many with combining sites interacting with five or six amino acid residues (cf. Arnon et al., 1965; Kabat, 1966; Twining et al., 1980, and references therein). Thus, the $60 \%$ amino acid sequence homology between human CA I and human CA II and their very similar topography by X-ray crystallography (Kannan, 1980) would lead to a prediction of some immunological cross-reactivity. For instance, bovine and guinea pig $\alpha$-lactalbumins, with about $60 \%$ homology in amino acid sequence, show a definite cross-reaction (Erickson and Rosenberg, 1973). Such crossreactions have probably not been found previously because binding studies of antibodies to carbonic anhydrases have not been previously performed.

We found that most polyvalent rabbit and mouse antisera showed 


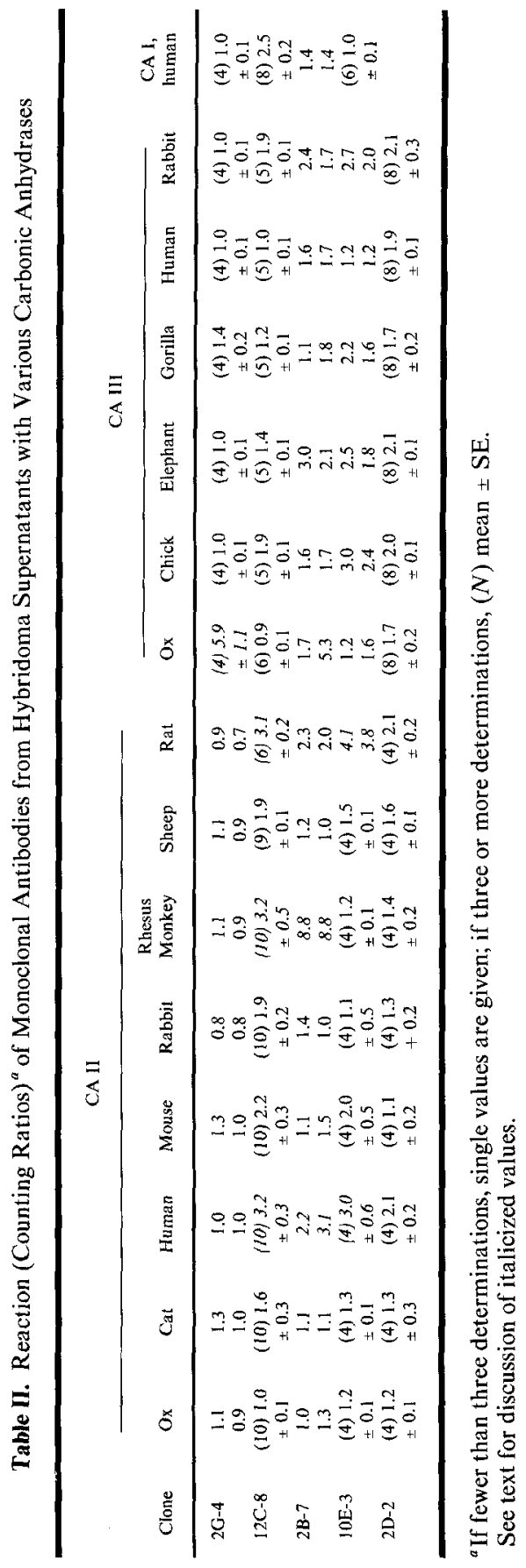


cross-reactions between CA I and CA II while weaker cross-reactions between CA III and CA I and/or CA II were found. Some of the differences in reactivity suggest that species-specific determinants are also being detected. For instance, anti-human CA I and anti-human CA II react better with human CA I or II than with bovine CA III (Figs. 2A, C, and D). Similarly, anti-bovine CA III reacts better with the homologous antigen than with the human CA III isozyme (Table II).

Monoclonal antisera raised by the hybridoma technique appeared to detect single haptens (as expected) since the cross-reactions were more individualized: one clone showed cross-reactions between CA II and CA III. Perhaps greater cross-reactions with CA I would have been detected if as many different species examples of CA I had been tested.

Of interest is the observation that several of the monoclonal anticarbonic anhydrase antibodies reacted more strongly with homologous CAs from species other than the immunizing species (Table II), e.g., 2B-7 reacted fourfold better with rhesus CA II than with the human CA II immunogen. Such idiosyncratic reactions of monoclonal antibodies are also being found in other systems. The recent report of a cross-reaction of anti-Thy 1.1 monoclonal antibody with vimentin was interpreted in terms of a possible shared carbohydrate between vimentin and Thy-1 (Dulbecco et al., 1981). An earlier report (Pillemer and Weismann, 1981) of cross-reaction of an anti-Thy 1 monoclonal with an anti-phosphorylcholine idiotypic specificity of mouse antibodies was interpreted in terms of possible evolutionary homology of the Thy 1 molecule with antibodies. (Since it is a very low percentage of homology, this degree of cross-reaction would not be expected, however.)

An alternative explanation of these cross-reactions may be the phenomenon of "half-site reactivity." In other words, monoclonal-secreting hybridomas are selected with such sensitive immunoassays that low-affinity antibodies are chosen. As Landsteiner demonstrated some years ago, in studies of artificial haptens, low-avidity antisera show quite wide cross-reactions with heterologous antigens (Landsteiner, 1946). Since an antibody combining site has a fairly fixed size, antibody production may be elicited to haptens which only partially correspond to the combining site. The potential for antigen binding by antibody when only a portion of the combining site is involved is suggested by fractionation studies of antihapten antibodies which detect some antibodies reacting with subportions of the hapten while others seem to be specific for the larger, total hapten (Pressman and Grossberg, 1973). This lack of specificity might especially be expected for $\operatorname{IgM}$ monoclonals since their maximal association constants, at least in the case of antilactosyl antibodies, are 50-fold lower than those for IgG monoclonals (Mandal and Karush, 1981). 


\section{REFERENCES}

Arnon, R., Sela, M., Yaron, A., and Sober, H. A. (1965). Polylysine-specific antibodies and their reaction with oligolysines. Biochemistry 4:948.

Carter, N. D., Hewett-Emmett, D., Jeffery, S., and Tashian, R. E. (1981). Testosterone-induced carbonic anhydrase isozyme of rat liver is indistinguishable from skeletal muscle carbonic anhydrase III. FEBS Lett. 128:114.

Claflin, J. L., Hudak, S., and Maddalena, A. (1981). Anti-phosphorylcholine hybridoma antibodies. I. Direct evidence for three distinct families of antibodies in the murine response. J. Exp. Med. 153:352.

Dodgson, S. J., Forster, R. E., Storey, B. T., and Mela, L. (1980). Mitochondrial carbonic anhydrase. Proc. Natl. Acad. Sci. USA 77:5562.

Dulbecco, R., Unger, M., Bologna, M., Battifora, H., Syka, P., and Okada, S. (1981). Cross-reactivity between Thy-1 and a component of intermediate filaments demonstrated using a monoclonal antibody. Nature 292:772.

Erickson, R. P., and Rosenberg, L. T. (1973). The role of tolerance in the lack of cross-reactivity between homologous (structurally related) proteins: Cross-reactions between $\alpha$-lactalbumins and between lysozymes recognized by antibodies from intolerant rabbits. $J$. Immunochem. 10:467.

Fine, J. M., and Laurent, G. (1970). Immunological studies of the carbonic anhydrases isolated from human and animal erythrocyte hemolysates. Progr. Immunobiol. Stand. 4:411.

Fraker, P. J., and Speck, J. C., Jr. (1978). Protein and cell membrane iodinations with a sparingly soluble chloramide 1, 3, 4, 6-tetrachloro-3 $\alpha, 6 \alpha$-diphenyl-glycoluril. Biochem. Biophys. Res. Comm. 80:849.

Gefter, M. L., Margulies, D. H., and Scharff, M. D. (1977). A simple method for polyethylene glycol-promoted hybridization of mouse myeloma cells. Somat. Cell Genet. 3:231.

Herzenberg, L. A., and Herzenberg, L. A. (1978). Mouse immunoglobulin allotypes. In Weir, D. M. (ed.), Handbook in Experimental Immunology, 3rd ed., Blackwell Scientific, Oxford, p. 12.21 .

Kabat, E. A. (1966). The nature of an antigenic determinant. J. Immunol. 97:1.

Kannan, K. K. (1980). Crystal structure of carbonic anhydrase. In Baurer, C., Gros, G., and Bartels, H. (eds.), Biophysics and Physiology of Carbon Dioxide, Springer-Verlag, New York, pp. 184-205.

Kishida, K., and Ochi, N. (1980). Evidence for the existence of two carbonic anhydrase isozymes in rabbit ciliary body. Experientia $36: 42$.

Klinman, N. R. (1972). The mechanism of antigenic stimulation of primary and secondary clonal precursor cells. J. Exp. Med. 136:241.

Landsteiner, K. (1946). The Specificity of Serological Reactions, rev. ed., Dover reprint of 1962, Dover, New York, pp. 270-272.

Littlefield, J. W. (1964). Selection of hybrids from matings of fibroblasts in vitro and their presumed recombinants. Science 145:709.

Mandal, C., and Karush, F. (1981). Restriction in IgM expression. III. Affinity analysis of monoclonal anti-lactose antibodies. J. Immunol. 127:1240.

Margulies, D. H., Kuehl, W. M., and Scarff, M. D. (1976). Somatic cell hybridization of mouse myeloma cells. Cell 8:405.

McKinley, D. N., and Whitney, P. L. (1976). Particulate carbonic anhydrase in homogenates of human kidneys. Biochim. Biophys. Acta 445:780.

Michili, A., and Buzzi, C. (1964). Electrophoretic and immuno-electrophoretic studies on the carbonic anhydrase of the human red blood cells. Biochim. Biophys. Acta 89:324.

Nonno, L., Herschman, H., and Levine, L. (1969). Serologic comparisons of the carbonic anhydrases of primate erythrocytes. Arch. Biochem. Biophys. 136:361.

Osborne, W. R. A., and Tashian, R. E. (1975). An improved method for the purification of carbonic anhydrase isozymes by affinity chromatography. Anal. Biochem. 64:297.

Pillemer, E., and Weissman, I. L. (1981). A monoclonal antibody that detects a V-TEPC15 idiotypic determinant cross-reactive with a Thy-1 determinant. J. Exp. Med. 153:1068. 
Pressman, D., and Grossberg, A. L. (1973). The Structural Basis of Antibody Specificity, W. A. Benjamin, Reading, Pa., pp. 148-165.

Rudikoff, S., Potter, M., Segal, D. M., Padlan, E. A., and Davies, D. R. (1972). Crystals of phosphorylcholine-binding Fab-fragments from mouse myeloma proteins: Preparation and X-ray analysis. Proc. Natl. Acad. Sci. USA 69:3689.

Suyama, H., Sawada, H., Ueda, H., and Ohya, I. (1968a). Erythrocyte carbonic anhydrases of the human and some animals. 3. Immunological study of human erythrocyte carbonic anhydrases. Med. Biol. (Jap.) 77:15.

Suyama, H., Sawada, H., Ueda, H., and Ohya, I. (1968b). Erythrocyte carbonic anhydrases of the human and some animals. 4. Immunological study of animal erythrocyte carbonic anhydrases. Med. Biol. (Jap.) 77:21.

Tashian, R. E. (1977). Evolution and regulation of the carbonic anhydrase isozymes. In Rattazzi, M. C., Scandalios, J. G., and Whitt, G. S. (eds.), Isozymes: Current Topics in Biological and Medical Research, Vol. 2, Alan R. Liss, New York, pp. 21-62.

Tashian, R. E., Shreffler, D. C., and Shows, T. B. (1968). Genetic and phylogenetic variation in the different molecular forms of mammalian erythrocyte carbonic anhydrases. Ann N.Y. Acad. Sci. 151:64.

Tashian, R. E., Hewett-Emmett, D., and Goodman, M. (1980a). Evolutionary diversity in the structure and activity of carbonic anhydrase. In Peeters, H. (ed.), Protides of the Biological Fluids, Vol. 28, Pergamon Press, Oxford, pp. 153-156.

Tashian, R. E., Hewitt-Emmett, D., Stroup, S. K., Goodman, M., and Yu, Y.-S. L. (1980b). Evolution of structure and function in the carbonic anhydrase isozymes of mammals. In Bauer, C., Gros, G., and Bartels, H. (eds.), Biophysics and Physiology of Carbon Dioxide, Springer-Verlag, New York, pp. 165-176.

Twining, S. S., Lehmann, H., and Atassi, M. Z. (1980). The antibody response to myoglobin is independent of the immunized species. Biochem. J. 191:681. 